\title{
PERANCANGAN MESIN OVEN KEMIRI BERBASIS SOLAR DRYER (MASKIRI-BSD)
}

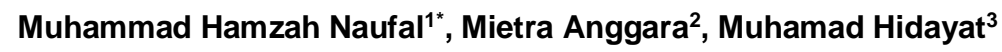 \\ ${ }^{1 *}$ Mahasiswa Jurrusan Teknik Mesin, Fakultas Teknik Universitas Teknologi Sumbawa \\ ${ }^{2}$ Dosen Jurusan Teknik Mesin, Fakultas Teknik Universitas Teknologi Sumbawa \\ ${ }^{3}$ Dosen Jurusan Teknik Mesin Fakultas Teknik Universitas Teknologi Sumbawa \\ ${ }^{*}$ Corresponding Author email: \\ 1Hamzahnaufal3@gmail.com, ${ }^{2}$ Mietra.Anggara@uts.ac.id, 3Muhamad.Hidayat@uts.ac.id
}

\begin{tabular}{|c|c|}
\hline & Abstrak \\
\hline Diterima & Kemiri (Aleurites moluccana Willd.) merupakan salah satu komoditi Hasil Hutan Bukan \\
\hline Bulan September & Kayu (HHBK) di Kecamatan Batulanteh, Sumbawa, Nusa Tenggara Barat, dengan luas \\
\hline 2019 & $\begin{array}{l}\text { lahan pada tahun } 2015 \text { sebesar } 595,7 \text { ha dan total produksi sebesar } 285,17 \text { ton (BPS, } \\
\text { 2017). Penanganan pasca panen dan pengolahan kemiri masih dilakukan secara } \\
\text { tradisional yaitu dimulai dari pengeringan dan pemecahan kemiri. Proses pengeringan }\end{array}$ \\
\hline Diterbitkan & biji kemiri dengan menggunakan sinar matahari langsung membutuhkan waktu 1-7 hari, \\
\hline Bulan Oktober & sedangkan kapasitas pengupasan kulit secara tradisional sebesar $5-6 \mathrm{~kg}$ per hari. \\
\hline 2019 & $\begin{array}{l}\text { Permintaan yang tinggi dengan produksi kemiri yang rendah mengakibatkan efisiensi } \\
\text { usaha menjadi rendah. Sehingga dibutuhkan suatu alat yang mampu mengeringkan } \\
\text { kemiri yaitu dengan Mesin Oven Kemiri Berbasis Solar Dryer (MASKIRI-BSD). }\end{array}$ \\
\hline Keyword: & MASKIRI-BSD menggunakan kolektor surya yang tersusun dari plat absorber \\
\hline Efisiensi, & berbentuk gelombang dengan tebal $0,4 \mathrm{~mm}$ dengan nilai konduktivitas $(\mathrm{k}) 11,2 \mathrm{~W} / \mathrm{m}^{0}$. \\
\hline Aleurites & Selain itu menggunakan penutup kaca bening dengan tebal $3 \mathrm{~mm}$ dengan kemiringan \\
\hline moluccana Willd., & kolektor $18^{\circ}$. Alat ini menggunakan rangka berupa aluminium hollow dan besi siku. \\
\hline PlatAbsorber & MASKIRI-BSD dapat menghasilkan rata-rata $\mathrm{T}$ out sebesar $82.01^{\circ} \mathrm{C}$ dari $\mathrm{T}$ in sebesar \\
\hline bentuk & $36^{\circ} \mathrm{C}$ sehingga, pengeringan kemiri hanya berlangsung selama $1,5-2$ hari, hal ini lebih \\
\hline Gelombang, Solar & efektif dan efisien dibandingkan dengan pengeringan tradisional. Penggunaan \\
\hline Dryer & $\begin{array}{l}\text { MASKIRI-BSD juga mempercepat tingkat titik impas yang diperoleh, yaitu hanya } \\
\text { dalam waktu } 3 \text { jam atau } 0,14 \text { kali pengeringan, sehingga pengusaha lebih cepat } \\
\text { mendapatkan laba. }\end{array}$ \\
\hline
\end{tabular}

\section{PENDAHULUAN}

Indonesia merupakan salah satu negara yang kaya akan keanekaragaman hayati, berbagai komoditas tanaman dapat tumbuh di Indonesia dengan mudah. Nusa Tenggara Barat, khususnya Kabupaten Sumbawa adalah salah satu provinsi yang kaya akan komoditas tanaman perkebunan (komoditas hutan bukan kayu) dan hutan kayu. Kemiri (Aleurites moluccana Willd.) merupakan salah satu komoditi Hasil Hutan Bukan Kayu (HHBK) di daerah Sumbawa khususnya di Kecamatan Batulanteh, Sumbawa, Nusa Tenggara Barat. Kecamatan Batulanteh, Desa Batudulang merupakan penghasil kemiri tertinggi di Kabupaten Sumbawa dengan luas lahan pada tahun 2015 sebesar 595.7 ha dan total produksi sebesar 285.17 ton (BPS, 2017).

Batulanteh, sebagai penghasil kemiri terbesar di Kabupaten Sumbawa memiliki sekitar $60 \%$ pengusaha yang mengelola lahan berupa kebun seluas lebih dari dua hektar per rumah tangga yang umumnya ditanami kemiri dan kopi. Menurut Muktasam et al. (2016) sekitar $80 \%$ pengusaha di Batulanteh masih menjual kemiri dalam bentuk gelondongan, hanya $20 \%$ pengusaha yang telah menjual kemiri hasil pengolahan dengan menggunakan tekonologi sederhana. Teknologi sederhana yang diterapkan oleh sebagian besar pengusaha di Desa Batudulang adalah dengan menjemur kemiri di lantai atau parapara, kemudian menyiram dengan air agar kulit kemiri lepas dari ocenya, dan memecah cangkang kemiri. Proses pengeringan kemiri di Desa Batudulang masih bergantung pada radiasi matahari dengan temperatur rata-rata $36^{\circ} \mathrm{C}$, sehingga mereka membutuhkan waktu kurang lebih 1-7 hari untuk mendapatkan hasil pengeringan sesuai keinginan, sehingga kemiri yang dipecahkan dari cangkangnya tetap utuh. Waktu yang lama mempengaruhi mikroorganisme yang hidup dalam kemiri dan memungkinkan mikroorganisme merusak kualitas dari kemiri itu sendiri, sehingga dibutuhkan waktu yang lebih cepat untuk pengeringan.

Penanganan pasca panen dan pengolahan kemiri masih dilakukan secara tradisional mengakibatkan produktivitas dan efisiensi usaha menjadi rendah. Sehingga kualitas biji kemiri yang dihasilkan turut menurun sedangkan kapasitas 
pengupasan kulit secara tradisional sebesar 5-6 kg per hari, dengan kualitas biji utuh yang dihasilkan maksimal $40 \%$. Pengeringan secara tradisional ditentukan oleh radiasi matahari, apabila cuaca sedang cerah maka pengeringan dapat berjalan dengan baik. Sedangkan untuk cuaca sedang mendung atau hujan pengeringan tidak dapat dilakukan. Keadaan ini dapat menyebabkan pembusukan dan kerusakan pada kemiri. Apabila pengeringan secara mekanis (pengeringan buatan) menggunakan tambahan panas memberikan beberapa keuntungan diantaranya dapat memanfaatkan radiasi matahari yang kurang cerah, kapasitas pengering dapat dipilih sesuai dengan yang diperlukan, tidak memerlukan tempat yang luas, serta kondisi pengeringan dapat dikontrol. Pengering buatan ini memerlukan energi untuk memanaskan alat pengering, mengimbangi radiasi marahari, panas yang keluar dari alat, memanaskan bahan, menguapkan air bahan serta menggerakkan udara (Kartasapoetra, 1994).

Penanganan pasca panen dan pengolahan kemiri masih dilakukan secara tradisional mengakibatkan produktivitas dan efisiensi usaha menjadi rendah. Sehingga kualitas biji kemiri yang dihasilkan turut menurun sedangkan kapasitas pengupasan kulit secara tradisional sebesar 5-6 kg per hari, dengan kualitas biji utuh yang dihasilkan maksimal 40\%. Pengeringan secara tradisional ditentukan oleh radiasi matahari, apabila cuaca sedang cerah maka pengeringan dapat berjalan dengan baik. Sedangkan untuk cuaca sedang mendung atau hujan pengeringan tidak dapat dilakukan. Keadaan ini dapat menyebabkan pembusukan dan kerusakan pada kemiri. Apabila pengeringan secara mekanis (pengeringan buatan) menggunakan tambahan panas memberikan beberapa keuntungan diantaranya dapat memanfaatkan radiasi matahari yang kurang cerah, kapasitas pengering dapat dipilih sesuai dengan yang diperlukan, tidak memerlukan tempat yang luas, serta kondisi pengeringan dapat dikontrol. Pengering buatan ini memerlukan energi untuk memanaskan alat pengering, mengimbangi radiasi marahari, panas yang keluar dari alat, memanaskan bahan, menguapkan air bahan serta menggerakkan udara (Kartasapoetra, 1994).

\section{METODE PENELITIAN}

Penelitian ini menggunakan metode eksperimental dengan 3 variabel yaiitu: variabel Terikat berupa intensitas radiasi matahari, kadar air kemiri, waktu yang dibutuhkann dalam pengeringan, dan temperatur MASKIRI-BSD; Variabel Bebas berupa perbandingan antara proses pengeringan tradisional dengan proses pengeringan menggunakan MASKIRI-BSD; dan Variabel terkontrol yang merupakan faktor-faktor lain yang dapat mempengaruhi hasil reaksi dan dikendalikan agar tidak mempengaruhi variabel bebas seperti proses pengambilan kemiri dari Desa Batu Dulang.

Penelitian ini dilaksanakan di Workshop Teknik Mesin, Faktultas Teknik Universitas Teknologi Sumbawa. Kegiatan ini dilaksanakan selama 5 bulan yaitu bulan April-Agustus 2018. Adapun alur penelitian yang dilakukan yaitu:

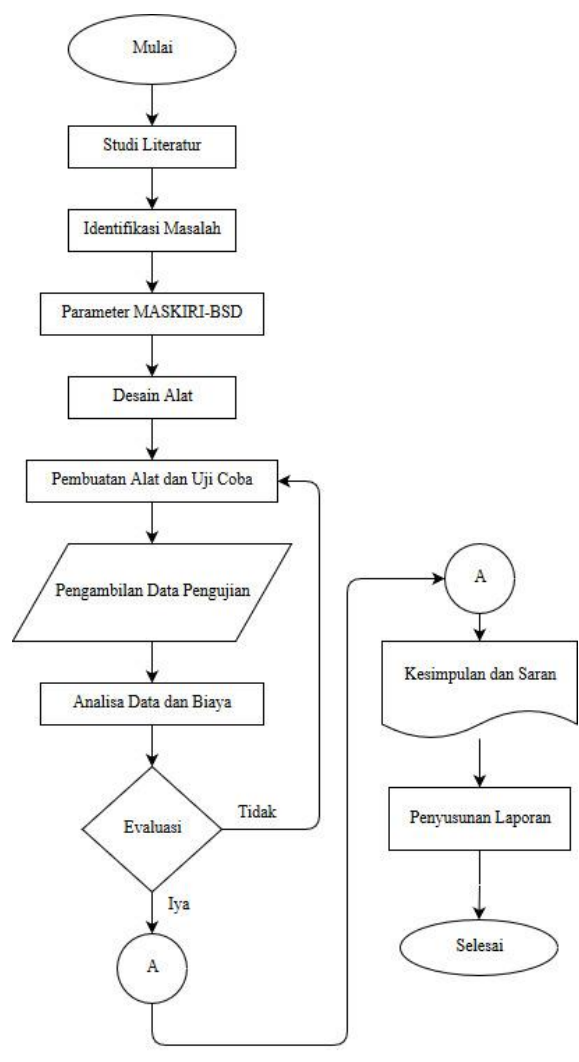

Gambar 1. Alur Penelitian

a. Alat dan Bahan

Alat yang digunakan dalam pembuatan MASKIRI-BSD adalah mesin bor listrik, masom las, gerinda, besi siku, dan penggaris siku. Adapun alat yang digunakan dalam penelitian guna uji MASKIRI-BSD adalah data logger NTC 12 channel sebagai pengukur temperatur dan piranometer untuk mengukur radiasi matahari.

Bahan yang digunakan dalam pembuatan MASKIRI-BSD adalah kaca dengan ketebalan 3 dan $5 \mathrm{~mm}$, alluminium hollow, plat seng bergelombang, triplek dengan ketebalan $3 \mathrm{~mm}$, lem sillicone, cat hitam doff, dan biji kemiri yang digunakan sebagai bahan penelitian.

b. Gambar Skema Alat

Gambar skema alat merupakan salah satu media untuk menerjemahkan ide rancangan sebelum menjadi alat yang diinginkan. Skema alat diperlukan agar dapat memudahkan dalam proses pabrikasi. Gambar teknik harus memperhatikan 
dimensi dari alat dan skala, dilakukan dengan bantuan software perancangan alat/ mesin seperti inventor.

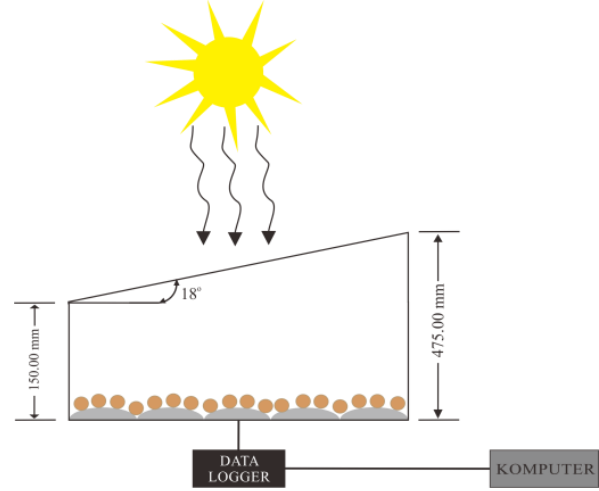

Gambar 2. Gambar Skema Alat MASKIRI-BSD

\begin{abstract}
Setelah semua perencanaan dalam perancangan alat MASKIRI-BSD selesai dilakukan, maka tindakan selanjutnya adalah proses pabrikasi. Pada tahap ini semua dimensi dan gambar dibuat dibentuk nyata, bentuk 3 dimensi.
\end{abstract}

c. Perancangan Alat Solar Drayer

Proses perancangan produk merupakan pengembangan alternatif dalam bentuk skema atau skets menjadi produk atau benda teknik yang bentuk, material dan dimensi elemen-elemennya ditentukan. Proses perancangan produk diawali dengan analisa teknik dan diakhiri dengan perancangan detail yang kemudian dituangkan dalam gambar teknik untuk proses pembuatannya.

Proses perancangan alat MASKIRI-BSD terbagi atas rancangan fungsional dan rancangan struktur alat. Adapun rancangan fungsional MASKIRI-BSD adalah sebagai berikut :

Tabel 3. Rancangan Fungsional MASKIRI-BSD

\begin{tabular}{|c|c|c|}
\hline No & $\begin{array}{c}\text { Nama } \\
\text { Bagian }\end{array}$ & Fungsi \\
\hline 1. & $\begin{array}{l}\text { Ruang } \\
\text { Vakum }\end{array}$ & $\begin{array}{l}\text { Ruang vakum berfungsi } \\
\text { sebagai tempat terjadinya } \\
\text { pengeringan. } \\
\text { dinding ruang vakum terdapat } \\
\text { kaca-kaca yang berfungsi } \\
\text { memasukan radiasi matahari } \\
\text { yang dibutuhkan selama } \\
\text { proses pengeringan kemiri. }\end{array}$ \\
\hline 2. & $\begin{array}{l}\text { Plat } \\
\text { absorber } \\
\text { bergelomba } \\
\text { ng }\end{array}$ & $\begin{array}{l}\text { Lantai ruang MASKIRI-BSD } \\
\text { terdapat plat } \\
\text { bergelombang } \\
\text { hitam yerwarna } \\
\text { tempat untuk menaruh biji } \\
\text { kemiri kering dan berfungsi } \\
\text { untuk mengkonversikan } \\
\text { radiasi matahari menjadi } \\
\text { energi panas. }\end{array}$ \\
\hline
\end{tabular}

Pada setiap sisi MASKIRI-

3. Triplek BSD terdapat triplek yang berguna sebagai isolator atau sebagai penahan panas.

Kaki penyangga ini berfungsi sebagai dudukan dari seluruh bagian MASKIRI-BSD guna mempermudah pengguna untuk memasukan dan mengeluarkan kemiri.

Adapun rancangan struktur alat berupa Prototype MASKIRI-BSD ini berdimensi $100 \mathrm{~cm} \mathrm{x}$ $100 \mathrm{~cm}$ x 47,5 cm, dengan atap kaca yang dibuat miring dengan kemiringan $18^{0}$. Bahan-bahan yang digunakan dalam pembuatan prototype alat pengering kemiri berbasis solar dryer sederhana ini dibuat dalam bentuk skala prototype dengan kapasitas $5 \mathrm{~kg}$ kemiri. Penutup kemiri dibuat dari kaca dengan ketebalan $3 \mathrm{~mm}$ untuk meneruskan radiasi matahari ke permukaan pelat penyerap.

d. Prosedur Penelitian

1. Persiapan Penelitian

Persiapan penelitian dilakukan dengan melakukan studi literatur untuk memperoleh masukan informasi dari buku referensi dan jurnal penelitian yang akan dilakukan. Setelah melakukan studi literatur, penulis melakukan observasi lapangan dengan melakukan pengamatan kinerja pengeringan tradisional kemiri yang berada di Batulanteh.

2. Persiapan Instalasi Penelitian Persiapan instalasi penelitian dilakukan dengan mempersiapkan lokasi penelitian dan menyiapkan bahan serta peralatan yang dibutuhkan.

3. Proses Pembuatan MASKIRI-BSD

Pada tahap awal dilakukan pembuatan kontruksi/ rangja MASKIRI-BSD, rangka kolektor terbuat dari besi siku dimana ukuran bagian dalam kolektor berbentuk persegi. Selanjutnya pembutan plat absorber berbentuk alur $\mathrm{V}$ dengan sudut $45^{\circ}$, pemasangan kaca dengan kemiringan $18.4^{\circ}$ sehingga kaca dapat meneruskan radiasi matahari dengan optimal dan pemasangan isolasi (triplek) pada bagian sisi bawah, samping kiri-kanan, dan pada sisi belakang.

4. Pengujian Alat dan Pengambilan Data

Pengujian alat dan pengambilan data dilakukan setelah pembuatan MASKIRIBSD berhasil. Pengambilan data dimulai pada pukul 07.30 sampai dengan 15.30 WITA dalam kondisi cuaca cerah. MASKIRI-BSD diletakkan dibawah radiasi matahari secara langsung, dan 
memposisikannya sesuai dengan arah matahari untuk daerah Sumbawa Besar dengan posisi 8,88 LS dan 117,46 BT. Menurut Anggara (2016), posisi matahari akan cenderung pada lintang utara, sehingga alat diposisikan menghadap utara - selatan.

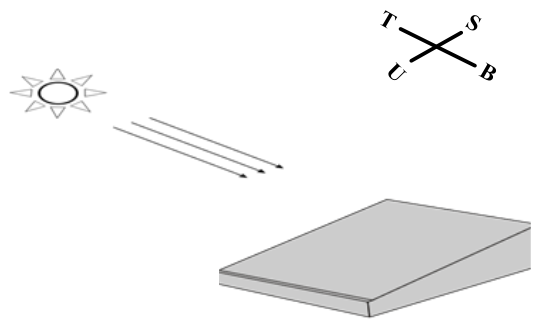

Gambar 4. Posisi peletakan alat MASKIRI-BSD terhadap matahari

Setelah posisi MASKIRI-BSD ditata dengan tepat, kemiri dimasukkan kedalam mesin oven sebanyak 1000 g. Kemudian dilakukan pengukuran terhadap beberapa parameter berupa jumlah kapasitas alat, temperatur yang dihasilkan dalam pengeringan, kadar air kemiri dan analisis ekonomi alat.

\section{Temperatur}

Pengukuran temperatur yang dilakukan pada beberapa titik pengukuran untuk melihat sebaran temperatur. Adapun temperatur yang diukur meliputi temperatur lingkungan dan temperatur plat seng absorber berwarna hitam dengan sistem pengambilan data kontinyu per 5 menit menggunakan thermocouple (data logger 12 channel).

\section{Kadar Air Bahan}

Pengukuran kadar air bahan dilakukan dengan menimbang berat sebelum pengeringan dan sesudah pengeringan. Kemudian dilakukan perhitungan dengan $\%$ basis kering (persamaan 2). Setelah didapatkan kadar air pengeringan, maka kadar air awal sebelum pengeringan dikurangi dengan kadar air setelah pengeringan (3).

$$
\text { Kadar Air Bahan }=\mathrm{M}_{1}-\mathrm{M}_{2}
$$

Keterangan :

$$
\begin{aligned}
\text { M1 }= & \text { Kadar air sebelum pengeringan } \\
& 10,38 \% \text { bk (Tarigan, 2007) } \\
\text { M2 } & \text { Kadar air setelah pengeringan } \\
& \text { \%bk (persamaan } 2)
\end{aligned}
$$

\section{Radiasi Surya}

Pengambilan data radiasi surya dilakukan dengan cara pengukuran menggunakan piranometer yang terdapat pada stasiun cuaca, Universitas Teknologi Sumbawa.

\section{Mutu Bahan}

Mutu bahan hasil pengeringan dianalisa melalui sistem pemecahan biji kemiri. Pengeringan dikatakan telah berhasil jika biji kemiri dapat dipecahkan tanpa menghancurkan kernel.

\section{HASIL DAN PEMBAHASAN}

\section{Hasil Penelitian}

Hasil yang didapat dalam penelitian mesin oven kemiri berbasis solar dryer (MASKIRI-BSD) adalah prototype MASKIRI-BSD, hasil pengujian kadar air, hasil pengujian temperatur, dan analisis ekonomis alat. Hasil penelitian ini dapat dilihat dari beberapa indikator pencapaian dibawah ini :

a. Bentuk Alat

Prototype MASKIRI-BSD ini berdimensi $100 \mathrm{~cm}$ x $100 \mathrm{~cm}$ x 47,5 cm dengan atap kaca yang di buat miring dengan kemiringan $18^{\circ}$. Bahanbahan yang digunakan dalam pembuatan prototype mesin ini mempunyai karakter khusus yaitu, dipilih bahan dengan harga yang sangat terjangkau dengan melihat kemampuan masyarakat, selanjutnya bahan ringan dan mudah dalam pengoperasiannya serta menggunakan kolektor panas yang tinggi sehingga mempercepat proses pengeringan kemiri.

Alat pengering kemiri berbasis solar dryer sederhana ini dibuat dalam bentuk skala prototype dengan kapasitas $5 \mathrm{~kg}$ kemiri. Penutup kemiri dibuat dari kaca dengan ketebalan $3 \mathrm{~mm}$ untuk meneruskan radiasi matahari ke permukaan pelat penyerap. Solar dryer ini berbentuk seperti sebuah ruangan tertutup dengan dinding dari kaca agar dapat meneruskan radiasi matahari ke pelat penyerap, serta dilapisi dengan bahan isolator dari triplek agar panas tidak keluar ke lingkungan. tertutupnya alat ini untuk menghindari udara yang keluar ke lingkungan karena memanfaatkan panas di ruang vakum untuk mengeringkan kemiri selain dari radiasi matahari langsung yang mengenai pelat penyerap.

b. Hasil Pengujian Kadar Air

Pengujian kadar air ini bertujuan untuk mengetahui besarnya kandungan air yang terdapat pada kemiri. Prinsip pengujian dilakukan dengan menghilangkan air dan zat-zat yang menguap dengan pemanasan pada temperatur maksimum $102.93{ }^{\circ} \mathrm{C}$ dalam keadaan vakum. Pengujian ini dilakukan untuk mengetahui lama pengeringan dan jumlah kadar air dengan menggunakan pengeringan alami dan menggunakan alat MASKIRI-BSD. Dari pengujian kadar air diperoleh hasil sebagai berikut : 
Tabel 1. Hasil Uji Kadar Air MASKIRI-BSD

\begin{tabular}{|c|c|c|c|}
\hline No & Jenis Sampel & $\begin{array}{l}\text { Kadar } \\
\text { Air }(\%)\end{array}$ & $\begin{array}{l}\text { Lama } \\
\text { Pengeringan } \\
\text { (hari) }\end{array}$ \\
\hline 1 & $\begin{array}{l}\text { Kemiri } \\
\text { pengeringan } \\
\text { MASKIRI-BSD }\end{array}$ & 4.63 & 2 \\
\hline 2 & $\begin{array}{l}\text { Kemiri } \\
\text { pengeringan alami }\end{array}$ & 5 & 7 \\
\hline
\end{tabular}

Berdasarkan data hasil uji kadar air ini dapat diketahui perbandingan kadar air antara kemiri yang dikeringkan dengan MASKIRI-BSD dan yang dikeringkan secara alami. Tarigan et al. (2007) mengemukakan bahwa tingkat kadar air yang paling sesuai untuk proses pemecahan kemiri adalah 4\% sampai 5\%. Berdasarkan referensi tersebut dapat dikatakan bahwa pengeringan dengan MASKIRI-BSD dalam waktu dua hari saja sudah memenuhi kriteria kadar air pada kemiri yang akan masuk untuk proses pemecahan.

Berdasarkan data diatas dapat diketahui bahwa kemiri yang dikeringkan menggunakan MASKIRI-BSD memiliki kadar air yang lebih rendah dibandingkan dengan pengeringan secara alami yaitu dengan kadar air $4.63 \%$ dengan $5 \%$.

\section{c. Hasil Pengujian Temperatur}

Pelaksanaan pengujian dilakukan pada pukul 7.30 WITA hingga 15.30 WITA dengan interval satu jam. Pengujian pada temperatur dan waktu pengeringan dilakukan untuk mengetahui peningkatan temperatur pada alat sesuai dengan perubahan waktu.Pengujian dilakukan pada tanggal 5-10 Juli 2018, yang berarti dilakukan tiga kali pengulangan pengeringan. Pengujian juga dilakukan dengan membandingkan pengeringan kemiri secara tradisional (Temperatur Lingkungan) dan pengeringan menggunakan MASKIRI-BSD (Temperatur MASKIRI-BSD).

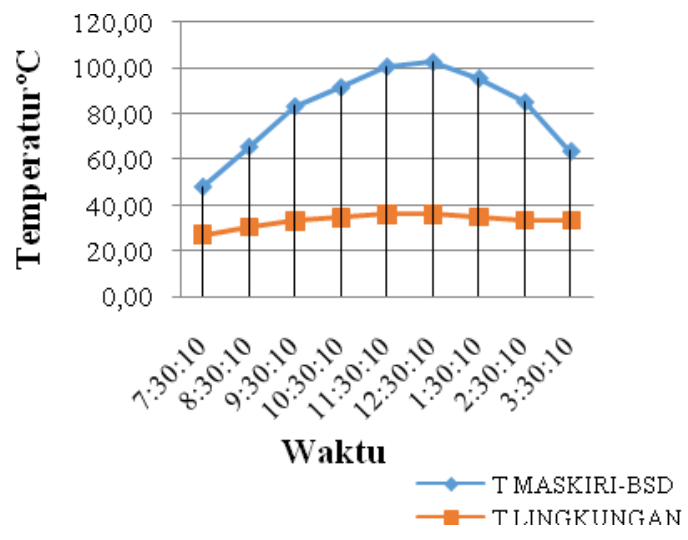

Gambar 5. Grafik Rata-rata Temperatur Hari Pertama Pengeringan

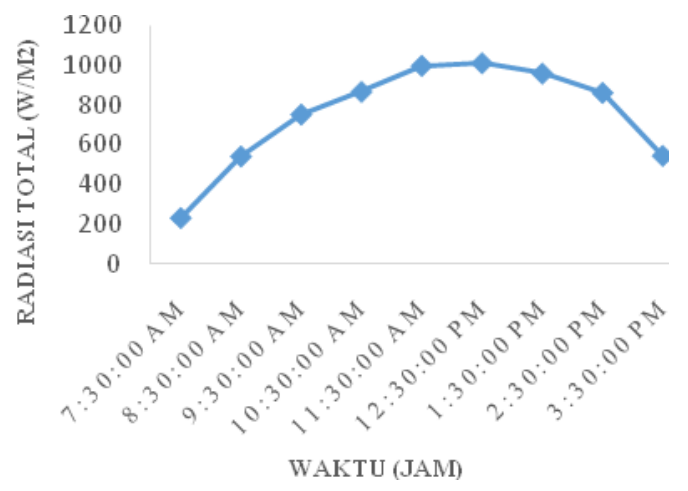

Gambar 6. Grafik Rata-rata Radiasi Matahari Pengeringan Hari Pertama

Dari data yang diperoleh, temperatur pengeringan mengalami fluktuasi. Sesuai dengan data radiasi matahari yang juga fluktuatif sesuai dengan temperatur yang dihasilkan (Gambar 4). Hal ini dipengaruhi oleh cuaca dan waktu pengeringan. Saat cuaca cerah sinar matahari akan tetap terserap dengan optimal karena tidak terhalang awan. Selain itu pengeringan akan efektif dan optimal jika dilakukan pada siang hari, karena intensitas cahaya yang dipancarkan cukup kuat. Pada Gambar 4.2 rata-rata temperatur pada hari pertama (Tanggal 5, 7, dan 9) didapatkan temperatur optimal pengeringan menggunakan MASKIRI-BSD pada pukul 12.30 WITA dengan temperatur sebesar $102.93{ }^{\circ} \mathrm{C}$. Sedangkan temperatur optimal untuk lingkungan terdapat pada pukul 12.30 WITA sebesar $36.21{ }^{\circ} \mathrm{C}$. 


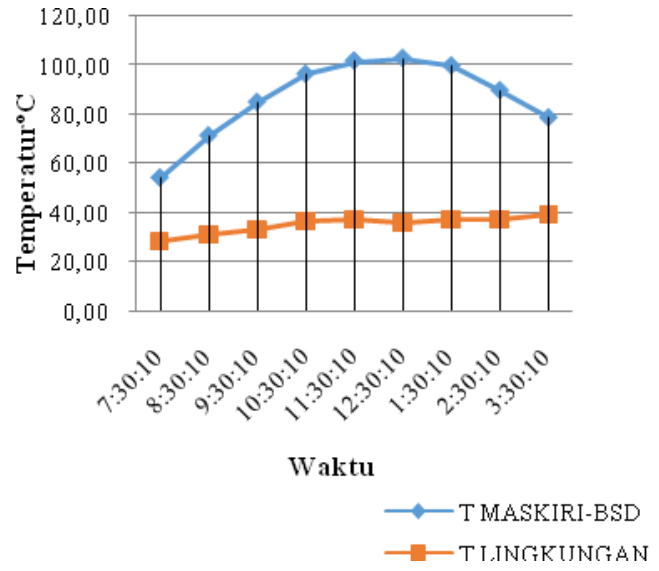

Gambar 7. Grafik Rata-rata Temperatur Pengeringan Hari Kedua

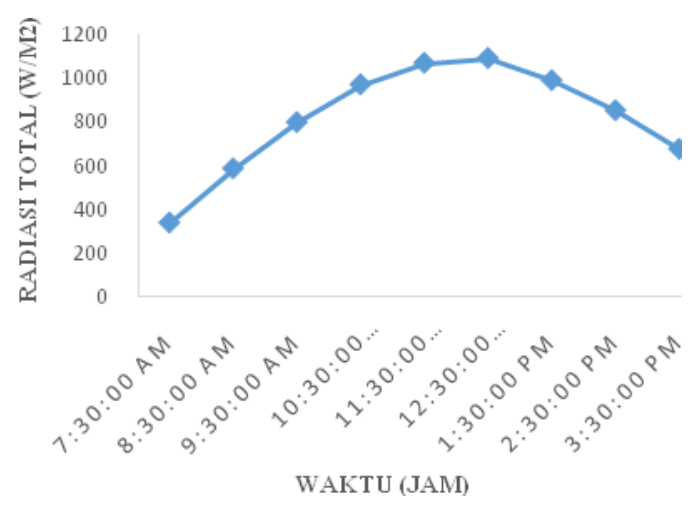

Gambar 8. Grafik Rata-rata Radiasi Matahari Pengeringan Hari Kedua

Pada Gambar 4.4 rata-rata temperatur pada hari kedua (Tanggal 6, 8, dan 10) didapatkan temperatur optimal pengeringan menggunakan MASKIRI-BSD pada pukul 12.30 WITA dengan temperatur sebesar $102.93{ }^{0} \mathrm{C}$. Sedangkan temperatur optimal untuk lingkungan terdapat pada pukul 15.30 WITA sebesar $39.45{ }^{\circ} \mathrm{C}$. Temperatur optimal yang terdapat dalam MASKIRI-BSD berbanding terbalik dengan temperatur lingkungan optimal, hal ini dikarenakan pada tanggal 8 dan 10 Juli keadaan lingkungan cukup berawan, sehingga intensitas cahaya yang masuk terhalang oleh awan. Pada Gambar 4 terdapat data radiasi matahari yang juga fluktuatif sesuai dengan temperatur yang dihasilkan MASKIRI-BSD.

Alat ini memiliki konsep green house yang bertujuan untuk merangkap panas. Kalor dari cahaya matahari terserap oleh alat namun tidak langsung dipantulkan keluar alat, namun dipantulkan kembali oleh dinding alat berulang kali dan dibuat dengan sistem vacum agar kalor yang dipantulkan keluar alat lebih lambat. Ini adalah konsep pemanfaatan energi kalor matahari dengan optimal. Hasilnya, MASKIRI-BSD merangkap kalor dari sinar matahari sehingga menyebabkan temperatur dalam alat lebih besar dari temperatur lingkungan (pengeringan alami).

Berdasarkan data yang diperoleh dapat diketahui perbandingan peningkatan temperatur antara pengeringan dengan MASKIRI-BSD dengan pengeringan secara alami. Pengeringan dengan MASKIRI-BSD mampu menghasilkan temperatur yang lebih tinggi dibandingkan dengan pengeringan alami. Dengan adanya temperatur didalam alat yang tinggi, tentu akan mendukung percepatan proses pengeringan. Sehingga, pengeringan dengan MASKIRI-BSD dapat dilakukan hanya dalam waktu 2 hari.

\section{d. Analisis Ekonomi Alat (MASKIRI-BSD)}

Analisis ekonomi sangat diperlukan untuk melihat reliabilitas dari alat yang dirancang oleh penulis dengan alat yang sebelumnya digunakan oleh masyarakat. Analisis ekonomi yang digunakan adalah BEP (Break Event Point/ Titik impas), yang dapat berfungsi untuk mengetahui hubungan antara penjualan, biaya, dan laba; mengetahui struktur biaya tetap dan biaya variabel; mengetahui kemampuan perusahaan dalam menekan biaya dan batas dimana perusahaan tidak mengalami laba dan rugi; dan untuk mengetahui hubungan antara cost, volume, harga, dan laba (Harahap, 2008).

\section{MASKIRI-BSD:}

Berikut ini adalah analisis ekonomi dari
Waktu kerja

Jumlah pengangkut/hari

Harga produk

\section{Teknologi masyarakat}

$\begin{array}{ll}\text { Terpal }(6 \times 10 \mathrm{~m}) 5 \text { buah } & =\mathrm{Rp} 318,000.00 \times 5 \\ & =\mathrm{Rp} 1,590,000 / 1 \mathrm{thn} \\ \text { Kapasitas } & =100 \mathrm{~kg} \\ \text { Waktu Pengeringan } & =8 \text { hari } \\ \text { Harga Produk } & =\mathrm{Rp} 10,000.00 / \mathrm{kg} \\ \text { Hasil Pengeringan } & =86.34 \mathrm{~kg} / \text { pengeringan }\end{array}$

Tabel 1. Analisis Ekonomi Pengeringan Tradisional

\begin{tabular}{lccccc}
\hline Fixed Cost & $\begin{array}{c}\text { Harga } \\
\text { Awal }\end{array}$ & Ket. & $\begin{array}{c}\text { Total }(\mathrm{Rp} / \\
\text { tahun) }\end{array}$ & $\begin{array}{c}\text { Total } \\
(\mathrm{Rp} / \\
\text { hari })\end{array}$ & $\begin{array}{c}\text { Total } \\
(\mathrm{Rp} / \\
\text { Pengeri- } \\
\text { ngan) }\end{array}$ \\
\hline $\begin{array}{l}\text { Penyusutan } \\
\text { nilai }\end{array}$ & $1,590,000$ & $\begin{array}{c}\text { Umur } \\
\text { pakai } 1\end{array}$ & $1,590,000$ & 4,543 & 36,343 \\
\hline
\end{tabular}


ekonomi terpal

\begin{tabular}{cccccc}
\hline $\begin{array}{c}\text { Variable } \\
\text { Cost }\end{array}$ & $\begin{array}{c}\text { Harga } \\
(\mathrm{Rp} / \mathrm{kg})\end{array}$ & $\begin{array}{c}\text { Jumlah } \\
\text { Penger } \\
\text { ingan } \\
\text { /hari }\end{array}$ & $\begin{array}{c}\text { Jumlah } \\
(\mathrm{kg} / \mathrm{hari})\end{array}$ & $\begin{array}{c}\text { Total } \\
(\mathrm{Rp} / \\
\text { hari })\end{array}$ & $\begin{array}{c}\text { Total } \\
(\mathrm{Rp} / \\
\text { Pengeri } \\
\text { ngan })\end{array}$ \\
\hline $\begin{array}{c}\text { Biaya } \\
\text { Angkut }\end{array}$ & 150.00 & 2 & 100.00 & $\begin{array}{c}30,00 \\
0.00\end{array}$ & $\begin{array}{c}240,000 \\
.00\end{array}$ \\
\hline
\end{tabular}

Jumlah Penjualan

(Rp/pengeringan)

: $\quad$ Rp $863,400.00$

Biaya Total (Rp/pengeringan) : $\quad$ Rp 276,342.86

Keuntungan (Rp/pengeringan) : Rp 587,057.14

BEP (Break Event Point)

0.47 pengeringan 4 hari

\section{Teknologi MASKIRI-BSD}

$\begin{array}{ll}\text { MASKIRI-BSD } & =\mathrm{Rp} 1,651,600.00 \\ \text { Kapasitas } & =5 \mathrm{~kg} \\ \text { Waktu Pengeringan } & =2 \mathrm{hari} \\ \text { Harga Produk } & =\mathrm{Rp} 10,000.00 / \mathrm{kg} \\ \text { Hasil Pengeringan } & =4.69 \mathrm{~kg} / \text { pengeringan }\end{array}$

Tabel 2. Analisis Ekonomi MASKIRI-BSD

\begin{tabular}{|c|c|c|c|c|c|}
\hline Fixed Cost & $\begin{array}{l}\text { Harga } \\
\text { Awal }\end{array}$ & Ket. & $\begin{array}{c}\text { Total }(\mathrm{Rp} / \\
\text { tahun) }\end{array}$ & $\begin{array}{l}\text { Total } \\
\text { (Rp/ } \\
\text { hari) }\end{array}$ & $\begin{array}{c}\text { Total (Rp/ } \\
\text { Pengeri- } \\
\text { ngan) }\end{array}$ \\
\hline $\begin{array}{l}\text { Penyusutan } \\
\text { nilai } \\
\text { ekonomi } \\
\text { MASKIRI- } \\
\text { BSD }\end{array}$ & $1,651,600$ & $\begin{array}{c}\text { Umur } \\
\text { pakai } 5 \\
\text { tahun }\end{array}$ & 330,320 & 943.7 & $1,887.5$ \\
\hline $\begin{array}{c}\text { Maintenance } \\
\text { Cost }\end{array}$ & \multicolumn{2}{|c|}{$\begin{array}{c}\text { Harga } \\
\text { (Rp/Tahun) }\end{array}$} & \multicolumn{2}{|l|}{$\begin{array}{c}\text { Total }(\mathrm{Rp} / \\
\text { hari })\end{array}$} & $\begin{array}{c}\text { Total }(\mathrm{Rp} / \\
\text { Pengeringan) }\end{array}$ \\
\hline Pemeliharaan & \multicolumn{2}{|c|}{200,000} & 571.43 & & $240,000.00$ \\
\hline
\end{tabular}

Jumlah Penjualan

(Rp/pengeringan)

: $\quad \operatorname{Rp} 46,900.00$

Biaya Total (Rp/pengeringan)

Rp 3,030.40

Keuntungan (Rp/pengeringan)

Rp 43,869.60

BEP

: 0,07 pengeringan

0,14 hari atau 3 jam

Berdasarkan hasil perhitungan analisis BEP pada pengeringan kemiri secara tradisional dan pengeringan kemiri menggunakan MASKIRIBSD didapatkan bahwa pengeringan menggunakan cara tradisional mencapai titik impas dalam 4 hari, dengan kata lain mencapai titik impas setelah 0,47 kali pengeringan. Pengeringan menggunakan MASKIRI-BSD mencapai titik impas dalam 3 jam dengan kata lain mencapai titik impas setelah 0,14 kali pengeringan. Penggunaan MASKIRI-BSD mengakibatkan tingkat titik impas semakin cepat diperoleh, sehingga pengusaha lebih cepat mendapatkan laba.

\section{PENUTUP}

\section{Kesimpulan}

1. Berdasarkan hasil penelitian dapat disimpulkan bahwa kinerja alat MASKIRI-BSD dalam meningkatkan temperatur dan menurunkan nilai kadar air di dalam ruang pengeringan bekerja dengan baik, pengeringan MASKIRI-BSD mendapatkan nilai kadar air $4.63 \%$ dengan rata-rata temperatur $82.01^{\circ} \mathrm{C}$. Pengeringan kemiri menggunakan MASKIRI-BSD lebih efektif dan efisien dengan lama pengeringan membutuhkan waktu 2 hari dibandingan pengeringan secara tradisional dengan waktu 7 hari, serta analisis ekonomi MASKIRI-BSD yang digunakan adalah analisis BEP, dengan menggunakan MASKIRI-BSD tingkat titik impas semakin cepat diperoleh, yaitu hanya dalam waktu 3 jam atau 0,14 kali pengeringan, sehingga pengusaha lebih cepat mendapatkan laba.

\section{REFERENSI}

Anggara M. 2016. Pengaruh Ukuran Butir Pasir Besi dan Volume Air Laut pada Absorber Type Finnsolar Destillation. Universitas Brawijaya.

Arlene A. 2010. Pengaruh Temperature dan Ukuran Biji Terhadap Perolehan Minyak Kemiri Pada Ekstraksi Biji Kemiri Dengan Penekanan Mekanis.Diunduh pada:http://repository.upnyk.ac.id/589/1/4 6.pdf.

Azharul K, Hawladerb M N A. 2004. Performance Investigation of Flat-Plate, V-Corrugated and Finned Air Collectors. Jurnal of Applied Thermal Engineering.

Azridjal A. 2004. Teknologi Rekayasa Surya sebagai Pemanas Udara untuk Proses Pengeringan (Solar dryer). Jurnal Momentum. Padang (ID): Institut Teknologi Padang.

Basri. 2017. Efisiensi Pengering Produk Menggunakan Alat Pengering Surya Type Down Draf. Kendari: Universitas Haluoleo

BPS (Badan Pusat Statistik). 2017. Luas Tanaman Perkebunan Rakyat di Kabupaten Sumbawa Dirinci per Kecamatan Tahun 2015 Diunduh pada

https://sumbawakab.bps.go.id/linkTableDi namis/view/id/126. 
Burhanuddin A. 2006. Karakteristik Kolektor Surya Plat Datar dengan Variasi Jarak Kaca Penutup dan Sudut Kemiringan Kolektor. Surakarta (ID): Universitas Sebelas Maret.

Danhil Z. 1990. Solar Teknik 1 \& 2. Padang (ID): Universitas Andalas.

Darmawan S., R Kurniadi. 2007. Studi pengusahaan kemiri di Flores NTT dan Lombok NTB. Info Sosial Ekonomi Vol.7 (2) Juni 2007: 117-129.

Delprete C, R Sesana. 2014. Mechanical characterization of kernel and shell of hazelnut: Proposal of an experimental procedure. Journal of Food Engineering. 124: 28-34.

Hanafri M A, A H Emawan, E Kustanti, E L Rahayu. 2006. Pembuatan Prototipe Alat Solar Dryer Berbasis Tenaga Surya Hybrid Sistem Portable. Institut Pertanian Bogor.

Handoyo E A. 2002. Jurnal Teknik Mesin Universitas PETRA. Surabaya: Universitas PETRA.

Hani M A. 2012. Pengeringan Lapisan Tipis Kentang (Solanum tuberosum. L.) Varietas Granola. Universitas Hasanudin.

Harahap S S. 2008. Teori Akutansi. Jakarta : PT Raja Grafindo Persada.
Kartasapoetra AG. 1994. Teknologi Penanganan Pasca Panen. Jakarta: Rhineka Cipta.

Khalid A. 2013. Optimasi Desain Alat Pengering Ikan Air Tawar Dengan Kapasitas $20 \mathrm{Kg}$ Memanfaatkan Energi Surya. Politeknik Negeri Banjarmasin.

Muktasam, E Amiruddin, dan P Aulia. 2016. Pengolahan Kemiri : Menciptakan Nilai Tambah dan Lapangan Kerja. Mataram: Lembaga Penelitian Universitas Mataram.

Safrizal R. 2010. Kadar Air Bahan. Teknik Pasca Panen. Jurusan Teknik Pertanian, Fakultas Pertanian, Universitas Syiah Kuala.

Sastro S J, Yuwana, E Silvia. 2014. Kinerja Alat Pengering Tenaga Surya YSD UNIB 12 Dalam Mengeringkan Kopi Robusta. Universitas Bengkulu.

Sinaga R. 2016. Karakteristik Fisik dan Mekanik Kemiri (Aleurites moluccana Wild.). Program Studi Teknik Mesin Pertanian dan Pangan, Institut Pertanian Bogor.

Tarigan E, G Prateepchaikul, R Yamsaengsung, A Sirichote, P Tekasakul. 2007. Dryingcharacteristics of unshelled kernelsof candlenuts. Journal of Food Engineering. 79: 828-833. 